\title{
Türkiye'de Yetişen Centaurea urvillei DC. subsp. urvillei' nin Antibakteriyel ve Antifungal Özelliği
}

\author{
Pınar Erecevit Sönmez*, Uğur Çakılcıoğlu \\ Munzur Üniversitesi, Tıbbi Hizmetler ve Teknikler Bölümü, Pertek Sakine Genç Meslek Yüksekokulu, Tunceli, \\ Türkiye \\ *perecevit @munzur.edu.tr ${ }^{\mathrm{D}}$, ucakilcioglu@yahoo.com (iD \\ Makale gönderme tarihi:29.08.2021, Makale kabul tarihi: 26.11.2021
}

\begin{abstract}
$\ddot{\mathbf{O} z}$
Türkiye florasının en büyük cinsi olan Centaurea L.' ya ait farklı türlerin etkinlikleri, ürettikleri bileşikler, insan sağlığı üzerine etkileri konusunda pek çok çalışma bulunmaktadır. Ancak Centaurea urvillei DC. subsp. urvillei’ nin kullanılabilir kısımlarının (toprak üstü olan yaprak, çiçek) patojen mikroorganizmalar karşı antimikrobiyal özellikleri üzerine ilgili herhangi bir çalışma yapılmamıştır.

Bu çalışmada C. urvillei DC. subsp. urvillei’ nin kullanılabilir kısımlarının metanoldeki çözeltisi uygulanarak insanlarda bulaşıcı hastalık yapan bakteri, maya, dermatofitler üzerinde oyuk agar ve mikrodilisyon yöntemi ile bu mikroorganizmaların gelişimini önleyip önlemediği ve en küçük duyarlılık miktarını öğrenmek amaçlanmıştır. Antimikrobiyal duyarlılık sonuçları incelendiğinde; bitki solüsyonu maya, dermatofit izolatları ve diğer bakterilerin çoğalmasını önleme üzerinde genel olarak duyarlı (14.66 mm-11.66 mm inhibisyon zon çap1 $\left.{ }^{-1}\right)$ bir inhibisyon bölgesi oluşturmuştur. $\mathrm{Bu}$ demektirki; C. urvillei DC. subsp. urvillei'nin $40 \mathrm{mg}$ 'lı dozu hastalı yapan tüm test mikroorganizmalarının (Escherichia coli ATCC 25922, Staphylococcus aureus ATCC 29213, Enterococcus faecalis ATCC 29212, Klepsiella pneumoniae klinik izolat1, Candida albicans RSKK 02007, Candida glabrata RSKK 014019, Candida tropicalis RSKK 02011, Epidermophyton floccosum RSKK 14024, Trichophyton rubrum RSKK 03022) çoğalmasını engelleyecek antibakteriyel ve antifungal özelliklere sahiptir. Kontrol grubu ile kiyaslandığında bakterilerde anlamlı bir değişsimin olmadığı maya ve dermatofitlerde ise anlamlı bir farklılığın olduğu belirlenmiştir ( $\mathrm{p}<0,0001 ; \mathrm{cd}$, $\mathrm{p}<0.001$; d). MIKK sınır değerleri 100-6.25 $\mu$ L'dir. Elde edilen veriler ile bu bitkinin patojenik mikroorganizmaların çoğalmasını azaltma kabiliyeti nedeniyle bulaşıcı hastalıkların tedavi ilaçları için bir kaynak olabilir.
\end{abstract}

Anahtar Kelimeler: Antibakteriyel ve antifungal aktivite, Centaurea urvillei DC. subsp. urvillei, patojen mikroorganizma

\section{Antibacterial and Antifungal Features of Centaurea urvillei DC. subsp. urvillei that is herboized in Turkey}

\footnotetext{
Abstract

Although there are many studies on the activities of different species, the compounds and effects of Centaurea L., the largest genus of the Turkish flora, on human health, no relevant studies have been conducted on the antimicrobial properties of the usable parts (above ground leaves, flowers) of C. urvillei DC. subsp urvillei against pathogenic microorganisms.

This study aimed to show whether it prevents the growth of these microorganisms that cause infectious diseases in humans on bacteria, yeast, dermatophytes that cause infectious diseases in humans via well agar and microdilution method by applying a methanol solution of the usable parts of $C$. urvillei DC. subsp. urvillei. Regarding the antimicrobial susceptibility results, the plant solution formed a generally sensitive inhibition zone (14.66 mm-11.66 mm inhibition zone ${ }^{-}$ ${ }^{1}$ diameter) on inhibition of growth of yeast, dermatophyte isolates and other bacteria. This means that $40 \mathrm{mg}$ dose of $C$. urvillei DC. subsp. urvillei has antibacterial and antifungal that can prevent the growth of all test microorganisms (Escherichia coli ATCC 25922, Staphylococcus aureus ATCC 29213, Enterococcus faecalis ATCC 29212, Klepsiella pneumoniae clinical isolate, Candida albicans RSKK 02007, Candida glabrata RSKK 014019, Candida tropicalis RSKK 02011, Epidermophyton floccosum RSKK 14024, Trichophyton rubrum RSKK 03022) that cause disease. It is seen when we compared with the control group that there was no significant difference in bacteria, however, a significant difference was observed in yeast and dermatophytes ( $<<0,0001$; $c d, p<0.001 ; d)$. MIK threshold values are 100-6.25 $\mu \mathrm{L}$. It has been
} 
proven with the obtained data that the ability of this plant to reduce the proliferation of pathogenic microorganisms can be a source for the cure of contagious diseases.

Keywords: Antibacterial and antifungal activity, Centaurea urvillei DC. subsp. urvillei, pathogenic microorganism

\section{GİRIŞ}

Bitkilerin insanlar tarafından tıbbi amaçlar doğrultusunda kullanılması insanlık kadar eskiye dayanmaktadır (Kendir ve Güvenç, 2010). Bitkiler yeni doğal tıbbi ürünlerin birincil kaynağıdır. Daha da önemlisi, bazı bitkilerin doğal ürünlerinde antienflamatuar, antikarsinojenik, antiaterosklerotik, antibakteriyel, antifungal, antiviral, antimutagenik ve antialerjik etkinlikler rapor edilmiştir (Mahlo ve ark., 2016). Bitkilere olan bu ilgi nedeniyle birçok bitki ekstresi fitokimyasal açıdan incelenmiş ve halk tıbbında tedavi amaçları ile bitki ekstrelerinin içeriklerinin karşılaştırılması yapılmıştır (Acet ve Özcan, 2017). Ayrıca Tüm dünyada alternatif tıbba yönelim, özellikle antibiyotik dirençli suşların meydana getirdiği enfeksiyon hastalıklarının neden olduğu problemlerin iyleştirilmesinde günden güne artmaktadır (Avşar ve ark., 2016; Karaca ve ark., 2017).

Centaurea türlerine Anadolu'da genellikle zerdali dikeni, timur dikeni ve peygamber çiçeği denilmektedir (Tozy1lmaz, 2019). Geleneksel Türk tıbbında bu türlerin balgam söktürücü antidiyabetik, antipiretik ve antidiarrhoeal olarak yaygın şekilde kullanılır (Boga ve ark., 2016). Etnobotanik raporlar Centaurea türlerinin antimikrobiyal, antifungal, antiülserojenic, antioksidan, antiplazmoidal, antiprotozoal, sitotoksik ve yara iyileşmesi, sindirim sistemi, mide, idrar söktürücü, astringent, hipotansif, müshil, analjezik, tonik, hemostatik gibi çeşitli biyolojik aktivitelere sahip olduğunu göstermiştir (Boga ve ark., 2016; Ozsoy ve ark., 2015).

Farklı Centaurea türlerinin türlerinin ürettikleri bileşiklerin, insan sağlığı üzerine etkileri konusunda pek çok çalışma bulunmaktadır (Aktumsek ve ark., 2013; Albayrak ve ark., 2017; Doğan Şığva ve ark., 2017; Köse ve ark., 2008; Kılıç, 2015; Ozsoy ve ark., 2015, Ozkan ve ark., 2016; Taştan ve ark., 2017: Alper ve ark., 2021; Tugay ve ark.,2021).

$\mathrm{Bu}$ araştırmalara göre; tıbbi öneme sahip olan Centaurea türlerinden Centaurea urvillei DC. subsp. urvillei'nin çalışma kapsamında değerlendirilmiş olmas1, antioksidan, antimikrobiyal, antitümoral özelliklere sahip çok sayıda sekonder metabolit açısından zengin bir genus oluşu (El-Najjar ve ark.,
2008; Koukoulitsa ve ark., 2002) çalışmanın konusu ve kapsamını vurgulamaktadır.

Doğal ürünler, hayati risk taşıyan hastalıklar dahil olmak üzere çeşitli koşullar için bazı tedavi edici ajanları içermeleri bakımından potansiyellere sahiptir (Karaca ve ark., 2017). Dolayıs1 ile çalışmamız bu olumsuzlukların çözülmesi açısından alternatif tedavi yaklaşımının gelişimine imkan sağlayacaktır.

Yapılan çalışmada Centaurea türlerinin sağlığa faydalı etkilerinin de saptanması düşük maliyetli olması, yan etkilerinin olmaması, toksik etkilerin az olmasından dolayı ilaçların yüksek dozlama stratejilerinin yerine tercih edilmesine imkan tanımak, ilaç elde edilen bitkilere olan talebi artırmak amaçlanmıştır. $\mathrm{Bu}$ çalışma bitkiler ile doğal yolarla üretilecek ilaç çalışmaları için ön araştırma niteliği taşımaktadır

Ek olarak in-vitro olarak incelenen Centaurea urvillei DC. subsp. urvillei'nin in vivo hayvan modellerinde araştırılması gerektiği kanısına varmaktayiz.

\section{MATERYAL VE METOT \\ Çalışmada Kullanılan Bitki}

$\mathrm{Bu}$ çalışmada tıbbi öneme sahip C. urvillei DC. subsp. urvillei'nin Elazığ ili Haziran ayında, Elazı ̆̆ ili Harput yolunda, yüksekliği 1350 m olan kayalıklar çevresinden toplanmıştır. Analize kadar uygun aseptik şartlarda laboratuvarda tutulmuştur. Bitki numunesi Doç. Dr. Uğur Çakılcıŏlu tarafından teşhis edilmiştir. Bitki Örnekleri Munzur Üniversitesi Herbaryumun da saklanmıştır.

\section{Antimikrobiyal Özellik \\ Çalışmada kullanılan bitkinin analize hazırlanması}

Bitki örneğinin uygun kısımlarından 10gram (gr) alınıp blender ile homojenize edilip steril cam erlenlere bırakılmıştır. Üzerine $50 \mathrm{~mL}$ metanol ilave edilmiş ve çözücü evaporatörde uzaklaştırılarak ekstraktlar hazırlanmıştır (Gupta ve ark., 2008). 
Sonra bu ekstraktların antimikrobiyal aktiviteleri belirlenmiştir.

\section{Çalışmalarda kullanılan test mikroorganizmaları}

$\mathrm{Bu}$ çalışmada 9 mikroorganizma kullanılmıştır. Bakteri olarak; Escherichia coli ATCC 25922, Staphylococcus aureus ATCC 29213, Enterococcus faecalis ATCC 29212, Klepsiella pneumoniae klinik izolatı maya olarak; Candida albicans RSKK 02007, Candida glabrata RSKK 014019, Candida tropicalis RSKK 02011, dermatofit fungus olarak Epidermophyton floccosum RSKK 14024, Trichophyton rubrum RSKK 03022 suşları kullanılmıştır. Bakteri suşları İstanbul Medical Park Göztepe Hastanesi Enfeksiyon Hastalıkları Klinik Mikrobiyoloji Laboratuvarından, mayalar ve dermatofit funguslar ise Refik Saydam Ulusal Tip Kültür Kolleksiyonundan elde edilmiştir. $\mathrm{Bu}$ mikroorganizmalar, önemli bitki ve insan patojenleri olmalarıyla beraber çok sayıda araştırmacı tarafindan çalışma konusu olan antibakteriyel ve antifungal kapasiteleri nedeniyle seçilmiştir.

\section{Mikroorganizma kültürlerinin hazırlanması ve ekim}

Bakteri suşları; Nutrient Broth'a aşılanacak $35 \pm 1^{\circ} \mathrm{C}$ 'de 24 saat, maya suşları; Yeast Malt Ekstrakt Broth'da ve dermatofit funguslar Glukozlu Sabouroud Broth'da $25 \pm 1{ }^{\circ} \mathrm{C}^{\prime} \mathrm{de} 48$ saat süre ile inkübe edilmiştir. Sıvı besiyerinde gelişen kültürler, McFarland (0.5) standart tüpüne göre bulanıklık ayarı yapıldıktan sonra buyyon tüplerine aktarılmıştır. Erlenmayerde steril edilen ve 45-50 ${ }^{\circ} \mathrm{C}$ 'ye kadar soğutulan Muller Hinton Agar, Yeast Malt Ekstrakt Agar ve Sabouraud Dextrose Agar yukarıda belirtildiği şekilde hazırlanan bakteri, maya ve fungusların buyyondaki kültürü ile $\% 1$ oranında aşılanacak (bakteri $; 10^{6} \mathrm{kob} \mathrm{mL}^{-1}$, maya ve fungus; $10^{4} \mathrm{kob} \mathrm{mL}^{-1}$ ) iyice çalkalandıktan sonra $9 \mathrm{~cm}$ çapındaki steril petri kutularına 15 'er mL konularak ve besiyerinin homojen bir şekilde dağılması sağlanmıştır.

\section{Oyuk Agar Metodu}

Katılaşan agar üzerine $6 \mathrm{~mm}$ çapında oyuk açılmıştır. Açılan oyuklara bir damla besiyerinden sonra $10 \mu \mathrm{l}$ ' de $20 \mathrm{mg}$ bitki numunesi aktarılmıştır. $\mathrm{Bu}$ şekilde hazırlanan petri kutuları $4^{\circ} \mathrm{C}$ 'de $1.5-2$ saat bekletildikten sonra bakteri aşılanan plaklar $37 \pm 1^{\circ} \mathrm{C}$ 'de 24 saat, maya ve dermatofit aşılanan plaklar ise $25 \pm 1{ }^{\circ} \mathrm{C}$ 'de 3 gün süre ile inkübe edilmiştir. Çalışma 3 paralel olarak yürütülecek ve sonuçlar ortalama değer olarak inhibisyon zonu $(\mathrm{mm})$ şeklinde değerlendirilmiştir (Özçelik, 1992; Collins ve Lyne 1987). Pozitif kontrol için standart antibiyotik diskler (bakteriler için ampisilin sulbaktam maya ve dermatofitler için mikostatin) kullanılmıştır. Tüm test mikroorganizmalarına karşı yapılan antimikrobiyal aktivite 3 kez tekrarlanmıştır.

\section{Mikrodilüsyon broth yöntemi (MİK)}

Bitki ekstraklarının mikroorganizmalara karşı Minimum inhibisyon konsantrasyonu'nu (MIK) belirlemek amacıyla mikrodilüsyon broth yöntemi kullanılmıştır (NCCLS, 2000; Erecevit Sönmez ve Çakılcıoğlu, 2020). Bakteriler için Muller Hinton Broth (Accumix ${ }^{\circledR}$ AM1072), maya ve dermatofit funguslar için Saboraud Dekstroz Broth (Himedia ME033) besiyerleri kullanılmıştır. Mikroorganizmaların pasajları bakteriler için $37 \pm 1$ ${ }^{\circ} \mathrm{C}^{\prime}$ de 18-24 saatlik broth kültürleri, maya ve dermatofit patojenleri için 72 saatlik broth kültürlerinde $\quad 25 \pm 0.1^{\circ} \mathrm{C}^{\prime} \mathrm{de}$ hazırlanmıştır ve bulanıklık 0.5 McFarland standardı'na göre ayarlanmıştır. Metanol içeren bitki solüsyonları önce maksimum $40000 \mu \mathrm{g}$ konsantrasyonda incelenmiştir ve ardından broth içeren aseptik mikrotitre plakaları üzerinde $100 \mu \mathrm{L}$ den $3.75 \mu \mathrm{L}$ 'ye kadar 6 kez seri 2 katlı dilüsyonları yapılmıștır. Bu seri seyreltmeler bir optik yoğunluk ölçerde okunan bakteri, maya, dermatofit mantarlarının broth kültürleri üzerinde test edilmiştir. Daha sonra üreme açısından incelenecek olan mikroplaklar bakteriler için $37 \pm 1{ }^{\circ} \mathrm{C}^{\prime} \mathrm{de} 18-24$ saat, maya ve dermatofit patojenleri için $25 \pm 0.1{ }^{\circ} \mathrm{C}$ 'de 72 saat inkübe edilmiştir. Bakteriler için $10^{6} \mathrm{kob} \mathrm{mL}$ 1, maya ve dermatofit funguslar için $10^{4} \mathrm{kob} \mathrm{mL}^{-1}$ olacak șekilde her kuyucuğa $50 \mu \mathrm{L}$ mikroorganizma süspansiyonu eklenmiştir. Mikroorganizmaların çoğalmasını önlemek için kullanılan bitkilerin nominal değeri için o numunenin en küçük değeri olarak tanımlanmıştır. Kuyucuklarda bulanıklığın olmadığı yani mikrobiyal büyüme olmayan son tüp kullanılan bitki örneklerinin MIKK değeri olarak kabul edilmiştir $\left(\mathrm{mg} \mathrm{mL}^{-1}\right)$. Test üç kez tekrarlanmıştır.

\section{İstatistik Analizi}

İstatistiksel analizler SPSS 20 (Windows) paket programı kullanılarak gerçekleştirildi. Verilerin normal dağılıma uygunluğu Shapiro Wilk testi ile değerlendirildi. Gruplar arasındaki farkl1lıkların 
belirlenmesinde One Way ANOVA ve çoklu karşılaștırmalarda Tukey testi kullanıldı. Nicel veriler ortalama \pm standart hata $(\mathrm{Ort} . \pm \mathrm{SH})$ olarak ifade edildi ve $p<0.05$ değerliği anlamlı kabul edildi.

\section{TARTIŞMA VE SONUÇ Antimikrobiyal Aktivite Sonuçları}

Tablo 1. test edilen mikroorganizmalar için metanol de çözünen $C$. urvillei DC. subsp. urvillei' nin oyuk agar metodu'na göre, Tablo 2. ve Şekil 1. minimum inhibitör konsantrasyonu'na göre antimikrobiyal özelliklerini göstermektedir. $\mathrm{Bu}$ Centaurea türünün hastalık yapıcı mikroorganizmaların üremesini engellenmeye başladığı ilk seyreltme konsantrasyonu $100 \mu \mathrm{L}$ olarak belirlenmiștir.

Metanol içinde çözünen C. urvillei DC. subsp. urvillei, maya ve dermatofit izolatları ve diğer bakterilerin çoğalmasını önleme üzerinde genel olarak anlamlı derecede duyarlı (14.66 mm- 11.66 $\mathrm{mm}$ inhibisyon zon çapi $^{-1}$ ) bir inhibisyon bölgesi göstermiştir $(\mathrm{p}<0.001 ; \mathrm{d})$. Buna göre; bitki E. coli üzerinde $14.6 \mathrm{~mm}$ inhibisyon $z^{-1}, S$. aureus ve $E$. faecalis' e karş1 12.6 ya da $12.7 \mathrm{~mm}$ inhibisyon zonu ${ }^{1}, K$. pneumoniae da ise 11.6 ya da $11.7 \mathrm{~mm}$ inhibisyon zonu ${ }^{-1}$ oluşturmuştur. $\mathrm{Bu}$ veriler bitkinin bakterisidal etkisinin sonucudur. Dermatofitler ve mayalar için ortalama inhibisyon bölgesi 8.6 ya da 8.7 mm'lik inhibisyon zonundan $14.6 \mathrm{~mm}$ 'lik bir inhibisyon zonuna kadar değişmektedir ve bu veri belirgin bir fungisidal etki (fungus hücrelerinin gelişimini veya üremesini önleyen) gösterdiğinin kanıtıdır. Ek olarak pozitif kontrol mikostatin 18.6 $\mathrm{mm}$ inhibisyon zonu ${ }^{-1}$ ile $34.6 \mathrm{~mm}$ inhibisyon zonu ${ }^{-1}$ arasında anlamlı derecede değişen yüksek bir etki göstermiştir $(\mathrm{p}<0.0001 ; \mathrm{cd})$.

Minimal inhibisyon konsantrasyonu test edilen mikroorganizmalar için incelendiğinde; (Tablo 2. ve Şekil 1.) metanol de çözünen $C$. urvillei'nin $E$. coli üzerinde çoğalmasını engellediği en düşük konsantrasyon; $6.25 \mu \mathrm{L}, S$. aureus, E. faecalis çoğalmasını engellediği en düşük konsantrasyon 12. $5 \mu \mathrm{L}, K$. pneumoniae üzerinde ise $25 \mu \mathrm{L}$ ' dir. Maya ve dermatofitlerin üremesini önleyen en düşük konsantrasyon ise $C$. albicans, $C$. glabrata üzerinde $25 \mu \mathrm{L}, C$. tropicalis; $100 \mu \mathrm{L}$, E. floccosum üzerinde $6.25 \mu \mathrm{L}, T$. rubrum üzerinde $12.5 \mu \mathrm{L}$ ' dir.

Bakterilerden; K. pneumoniae klinik izolatı, E. faecalis maya olarak; C. albicans, $C$. glabrata, $C$. tropicalis, dermatofit fungus olarak; E. floccosum, $T$. rubrum suşlarının üremesini engelemek için $C$. urvillei DC. subsp. urvillei'nin antimikrobiyal etkisi ilgili bir çalışma yapılmamıştır.

C. urvillei subsp. urvillei bitkisinin Candida krusei'ye karşı antifungal aktivite gösterdiği yapılan bir çalışmada belirtilmiştir. Ayrıca C. urvillei ssp. urvillei dahil üç Centaurea türü $100 \mathrm{mg}=\mathrm{mL}$ 'lik en yüksek test konsantrasyonunda hiçbir aktivite göstermediği ve $C$. urvillei Türkiye'deki floranın farklı alt türlerini temsil ettiği ancak alt tür adları belirtilmediği için yapılan çalışmada kesin bitki materyalleri bilinmediği ifade edilmiştir (Karamenderes ve ark., 2006). C. urvillei ssp. urvillei bitkisinin antimikrobiyal aktivite göstermemesi; bitkinin toplanma zaman1, coğrafi orjin, iklim, mikroorganizma çeşidi gibi faktörlere bağlı olarak değişikliğinden kaynaklanabileceği düşünülmektedir (Erecevit ve Kurbağ, 2017).

Aynı zamanda $C$. urvillei ssp. urvillei metanol ekstraktlarının mikrodilüsyon tekniği kullanılarak $E$. coli, Bacillus cereus, Salmonella enteritidis, $S$. aureus bakterilerine karşı antimikrobiyal etki gösterdiği ifade edilmiştir (Khammar ve Djeddi, 2012). Yaptığımız çalışmanın sonuçları ile karşılaştırdığımızda; E. coli, S. aureus bakterilerine karşı gösterdiği antibakteriyel etki ile paraleldir.

Tekeli ve ark. (2011) antibiyotiğe dirençli bakterilerin çok ciddi bir sorun oluşturduğu ve Centaurea ekstaktlarının bulaşıcı hastalıkların tedavisi için potansiyel yeni ilaçlara işaret ettiğini vurgulamıştır.

Başka bir çalışmada ise $C$. urvillei subsp. urvillei'nin metanol ekstraktının E. coli $(1000 \mathrm{mg}$ $\left.\mathrm{mL}^{-1} \mathrm{de}\right)$ ve $S$. aureus' a $\left(2000 \mathrm{mg} \mathrm{mL}^{-1}\right.$, de ) karş1 antibakteriyel aktivite gösterdiği ve doğal antibiyotik kaynağı olarak kullanılabileceği ifade edilmiştir (Tekeli, Zengin, Aktümsek, Sezgin, Torlak, 2011). Bizim elde ettiğimiz verilere bakıldığında; her iki bakteri (E. coli ve $S$. aureus) için uyumludur.

Farklı Centaurea türlerinin etkinlikleri, ürettikleri bileșikler, insan sağlığı üzerine etkileri konusunda pek çok çalışma bulunmaktadır. $C$. antiochia var. praealta' nın Alzheimer hastalığını tedavi etmek için bir tıbbi bitki olarak kullanılması ve doğal antimikrobiyal ajan etkinliğinin olması (Ozsoy ve ark. 2015), Centaurea türlerinden elde edilen seskiterpen yapısındaki bileşiklerin sitotoksik ve antitümoral özellikte olmaları (Doğan Şığva ve ark., 2017), C. balsamita, C. calolepis, C. cariensis subsp. 
maculiceps, C. cariensis subsp. microlepis, $C$. kotschyi var. kotschyi, C. solstitialis subsp. solstitialis, C. urvillei subsp. urvillei ve $C$. virgata türlerinin antibakteriyel aktiviteye sahip olmaları (Ozkan ve ark., 2016), C. wagenitzii, C. tossiensis, C. luscaniana türlerinin içerdiği essansiyal yağlar (Köse ve ark., 2008), Phlomis türlerinin içerdiği bu sekonder bileşiklerin çeşitliliği nedeniyle biyolojik aktivite araştırmaları ile in vivo şartlarda antidiyabetik, antialerjik, analjezik, antiülserojenik etkilerinin yanısıra, in vitro şartlarda damar koruyucu, antibakteriyel, antifungal etkileri ve antikanser aktivitelerinin araştırılması (Doğan Şığva ve ark., 2017), C. antiochia Boiss var. praealta (Boiss. \& Bal.) Wagenitz özütünün antioksidan, antiinflamatuar, asetilkolinesteraz (AChE) önleyici olması, yara iyileştirici antimikrobiyal bir ajan olarak da görev alması (Ozsoy ve ark., 2015), Elazığ Türkiye'den endemik bir bitki olan Psephellus pyrrhoblepharus (Boiss.) Wagenitz (C. pyrrhoblephara)'un sitotoksik potansiyelini değerlendirilmesi (Taştan ve ark., 2017), C. cynaus L. ve $C$. depressa Bieb. Türlerinin esansiyal yağ içeriğ $i$ araştırılması (Kılıç, 2015) C. amaena Boiss. \& Balansa ve $C$. aksoyi Hamzaoğlu \& Budak. fenolik içeriği ve biyolojik aktivitelerinin karşılaştırılması (Albayrak ve ark., 2017), dört Centaurea L. türünün yağ asidi içeriği ve antioksidan aktivitesinin değerlendirilmesi (Aktumsek ve ark., 2013) ile ilgili bir çok çalışma mevcuttur.
C. urviilei'nin başka bir alt türü olan $C$. urviilei subsp. stepposa'nin metanolik ekstarktının zengin bir fenolik içeriğe sahip olduğu ve diğer Centaurea türlerinin antioksidan etkisinin daha yüksek olduğu başka bir çalışmada ifade edilmiştir (Alper ve ark. 2021).

Farklı bir Centaurea türünün Bacillus, Pseudomonas, Staphylococcus, Streptococcus, Salmonella, Enterobacter, Enterococcus, Acinetobacter ve Escherichia cinsi üzerinde antibakteriyel etki gösterdiği belirtilmiştir (Fattaheian-Dehkordi ve ark.,2021).

\section{SONUÇLAR}

Daha önce bu Centaurea türünün kullanılabilir kısımlarının bakterilerden; $K$. pneumoniae klinik izolat1, E. faecalis maya olarak; C. albicans, $C$. glabrata, C. tropicalis, dermatofit fungus olarak; $E$. floccosum, T. rubrum suşlarının üremesini engelleme üzerindeki antimikrobiyal etkilerini inceleyen herhangi bir araştırma yapılmamıştır.

$\mathrm{Bu}$ çalışmada $C$. urvillei'nin hastalık yapan mikroorganizmalara karşı antibakteriyel ve antifungal etkileri belirlenmiştir. $\mathrm{Bu}$ nedenle alternatif ilaç çalışmalarında biyoaktif hammadde olarak kullanılabileceği önerilmektedir. 
Tablo 1. Oyuk agar yöntemi kullanılarak C. urvillei DC. subsp. urvillei ’nin patojenik mikroorganizmalar üzerindeki inhibitör etkileri

\begin{tabular}{l|c|c|c}
\hline Mikroorganizmalar & \multicolumn{2}{|c}{ İnhibisyon Bölgesi $(\mu \mathrm{L})$} & \\
\hline \multirow{2}{*}{ E. coli } & $\begin{array}{c}\text { Metanol ile } \\
\text { Hazırlanan } \boldsymbol{C} . \\
\text { urvillei DC. subsp. } \\
\text { urvillei }\end{array}$ & Metanol & Standart Antibiyotikler \\
\cline { 2 - 4 } S. aureus & $14.66 \pm 0.3^{\mathrm{d}}$ & - & $14.33 \pm 0.3^{*}$ \\
\hline E. faecalis & $12.66 \pm 0.3^{\mathrm{d}}$ & - & $14.33 \pm 0.3^{*}$ \\
\hline K. pneumoniae & $12.66 \pm 0.3^{\mathrm{d}}$ & - & $18.33 \pm 0.3^{*}$ \\
\hline C. albicans & $11.66 \pm 0.3^{\mathrm{d}}$ & - & $19.66 \pm 0.3^{*}$ \\
\hline C. glabrata & $11.66 \pm 0.3^{\mathrm{d}}$ & - & $28.33 \pm 0.33^{* *}$ \\
\hline C. tropicalis & $11.66 \pm 0.3^{\mathrm{d}}$ & - & $32.66 \pm 0.33^{* *}$ \\
\hline E. floccosum & $8.66 \pm 0.3^{\mathrm{d}}$ & - & $34.66 \pm 0.33$ \\
\hline T. rubrum & $14.66 \pm 0.3^{\mathrm{d}}$ & - & $18.66 \pm 0.33^{* *}$ \\
\hline & $12.66 \pm 0.3^{\mathrm{d}}$ & - & $18.66 \pm 0.33^{* *}$ \\
\hline
\end{tabular}

Negatif Kontrol: metanol, Pozitif Kontrol: ampisilin sulbaktam (*) ve mikostatin (**) (100 $\mu \mathrm{L}$ ve $20 \mu \mathrm{g}$ disk $\left.{ }^{-1}\right)$. Negatif kontrol: metanol. Zon çaplarının yorumlanması (mm); zon çapı $>11 \mathrm{~mm}$ (anlamlı derecede hassas; p<0,0001; cd, $\mathrm{p}<0.001 ; \mathbf{d})$, dirençli= $8-10$ c: $\mathrm{p}<0.01$, duyarlı değil $(-)(\mathbf{a}: \mathrm{p}>0.05)$.

Tablo 2. Minimum inhibisyon konsantrasyonu ile (MIK:100 $\left.\mu L ; m g ~ m L^{-1}\right)$ C. urvillei DC. subsp. urvillei'nin inhibitör etkisi

\begin{tabular}{|c|c|}
\hline \multirow[b]{2}{*}{ Mikroorganizmalar } & İnhibisyon Bölgesi $(\mu \mathrm{L})$ \\
\hline & $\begin{array}{c}\text { Metanol ile Hazırlanan C. urvillei DC. subsp. } \\
\text { urvillei'nin MİK Değerleri }\end{array}$ \\
\hline E. coli & 6.25 \\
\hline S. aureus & 12.5 \\
\hline E. faecalis & 12.5 \\
\hline K. pneumoniae & 25 \\
\hline C. albicans & 25 \\
\hline C. glabrata & 25 \\
\hline C. tropicalis & 100 \\
\hline E. floccosum & 6.25 \\
\hline T. rubrum & 12.5 \\
\hline
\end{tabular}




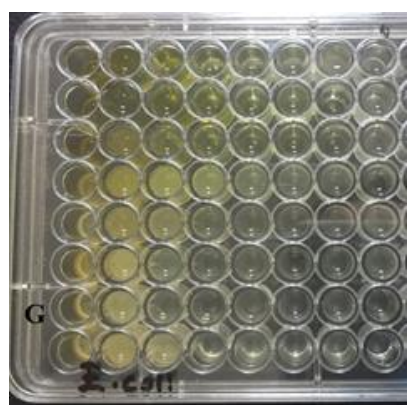

E. coli

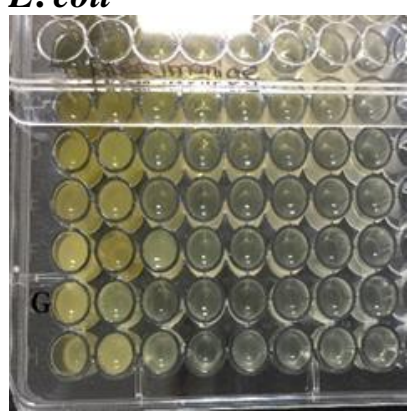

\section{K. pneumoniae}

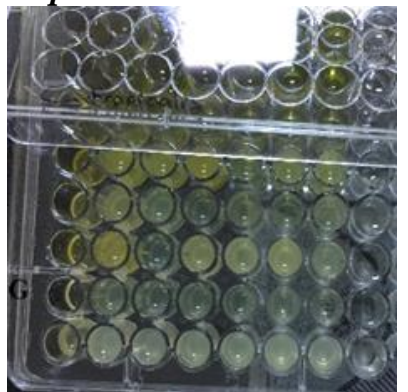

C. tropicalis

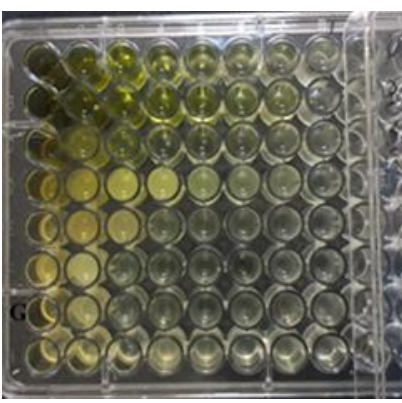

\section{S. aureus}

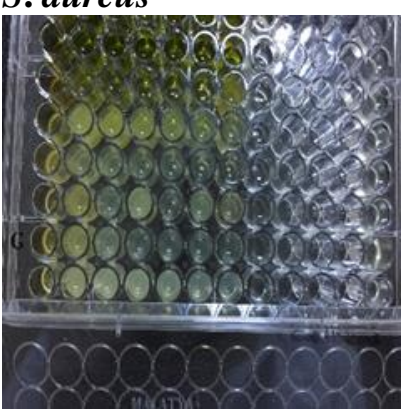

\section{C.albicans}

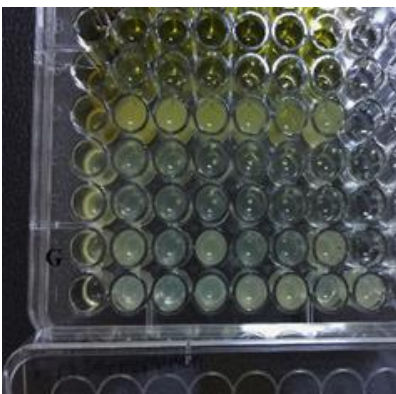

E. floccosum

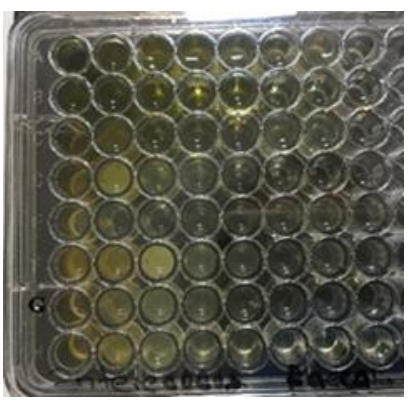

\section{E. faecalis}

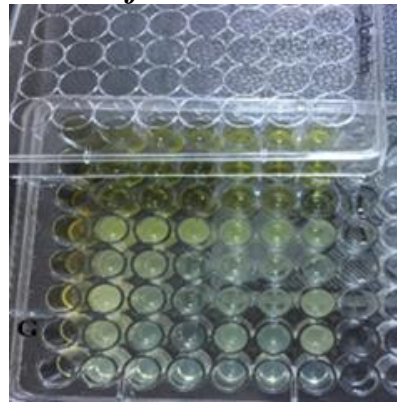

\section{C. glabrata}

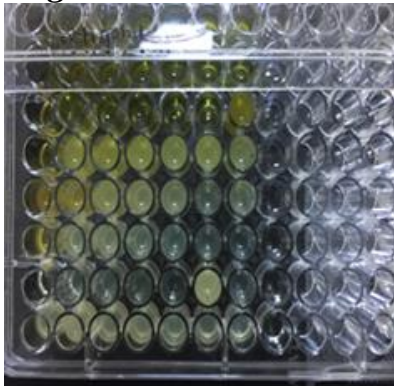

T. rubrum

Şekil 1. Minimum inhibisyon konsantrasyonu (MiK:100 $\mu \mathrm{L}$ ) ile C. urvillei DC. subsp. urvillei'nin antimikrobiyal özelliğinin mikrotiter'deki görünüşü

NOT: Mikrotiter da sekiz kuyu vardır. 1. kuyucuk; C. urvillei DC. subsp. urvillei'nin üzerine eklenmiş mikroorganizma kültürleri. Seyreltmeler mikrotiter içindeki 2. 7. ile 8. kuyucuklardan yapılmıştır. 2. ile 7. kuyucuklardan broth besiyeri ortami+(100, 50, 25, 12.5, 6.25, 3.75 mikrolitre metanol de hazırlanan C. urvillei DC. subsp. urvillei +mikroorganizma kültürleri). G harfi ile işaretlenmiş kuyucuklar, metanol içinde çözünmüş $C$. urvillei DC. subsp. urvillei'nin $100 \mu \mathrm{L}$ den $6.25 \mu \mathrm{L}$ 'ye kadar olarak adlandırılan konsantrasyonlarıdır. 


\section{ÇIKAR ÇATIŞMASI BEYANI}

Yazar/ Yazarlar bu makale ile ilgili herhangi bir çıkar çatışması bildirmemektedir.

\section{ARAŞTIRMA VE YAYIN ETÍĞİ BEYANI}

Yazar/Yazarlar bu çalışmanın araştırma ve yayın etiğine uygun olduğunu beyan eder.

\section{KAYNAKLAR}

Aktumsek, A., Zengin, G., Ozmen Guler, G., Cakmak, Y. S. ve Duran, A. (2013). Assessment of the antioxidant potential and fatty acid composition of four Centaurea L. taxa from Turkey. Food Chemistry, 141, 91-97. doi: 10.1016/j.foodchem.2013.02.092.

Avşar, C., Keskin, H., \& Berber, İ. (2016). Hastane infeksiyonlarından izole edilen mikroorganizmalara karşı bazı bitki ekstraktlarının antimikrobiyal aktivitesi. International Journal of Pure and Applied Science, 2, 22-29.

Albayrak, S., Atasagun, B. ve Aksoy, A. (2017). Comparison of phenolic components and biological activities of two Centaurea sp. obtained by three extraction techniques. Asian Pacific Journal of Tropical Medicine, 10, 599-606. doi: 10.1016/j.apjtm.2017.06.010.

Acet, T. ve Özcan, K. (2017). Investigation of some biological activities of Equisetum arvense plant used for medicinal purposes in Gümüşhane province. Turkish Journal of Agriculture- Food Science technology TURJAF, 5,1810-1814. doi:/10.24925/tu. rjaf.v5i13.1810-1814.1732

Alper, M., Özay, C., Güneş, H., Mammadov, R. (2021). Assessment of antioxidant and cytotoxic Activities and Identification of Phenolic Compounds of Centaurea solstitialis and Urospermum picroides from Turkey. Biological and Applied Sciences Brazilian Archives of Biology and technology, 64, 12. https://doi.org/10.1590/1678-43242021190530

Boga, M., Alkan, H., Ertaş A., Oral E. V., Yılmaz, M., Yeşil, Y., Gören, A. C., Temel, H. ve Kolak, U. (2016). Phytochemical profile and some biological activities of three Centaurea species from Turkey. Tropical Journal of Pharmaceutical Research. 15, 1865-1875.

Collins, C. H. ve Lyne, P. M. (1987). Mikrobiyological methods. 450 pp. London. Butter Morths \& Co (Publishers) Ltd.

Doğan Şığva, Z. Ö., Hasvatan, E. E., Gülen, G., Uslu, R, Eryıldız, B., Durmuşkaya, C., Kayalar, H., Özbilgin, A., Korkmaz, M. ve Gündüz, C. (2017). Effect of extracts of the endemic plants Centaurea lydia and Phlomis nissolii on Toxoplasma gondii. Turkish Journal of Parasitology, 41, 164-8. doi: 10.5152/tpd.2017.5451

El-Najjar, N., Dakdouki, S., Darwiche N., El-Sabban, M., Saliba, N. A. ve Gali-Muhtasib, H. (2008). Anti-colon cancer effects of Salograviolide A isolated from Centaurea ainetensis. Oncology Reports, 19, 897-904. doi:10.3892/or.19.4.897

Erecevit, P. ve Kırbağ, S., (2017). Some phytochemical effects of Pyrus communis L. (Pear) on the development of Saccharomyces cerevisiae as probiotic yeast. International Journal of Pure and Applied Science, 3,13-23.

Erecevit Sönmez, P. ve Çakılcığlu, U. (2020). Screening of Antimicrobial effect against microorganisms threatening to human health of the endemic plant; Centaurea saligna (C. Koch) Wagenitz from Turkey. Turkish Journal of Nature and Science, 9 (Özel Sayl), 23-27.

Fattaheian-Dehkordi, S., Hojjatifard, R., Saeedi, M., Khanav, M. (2021). A Review on antidiabetic activity of Centaurea spp.: A New. Approach for Developing Herbal Remedies. Evidence-Based Complementary and Alternative Medicine, 2021, 23. https://doi.org/10.1155/2021/5587938

Gupta, C., Garg, A. P., Uniyal, R. C. ve Kumari, A. (2008). Comparative analysis of the antimicrobial activity of cinnamon oil and cinnamon extract on somefood-borne microbes. African Journal of Microbiology Research, 2, 247-251. doi:10.5897/AJMR.9000180

Koukoulitsa, E., Skaltsa, H., Karioti, A., Demetzos, C. ve Dimas, K. (2002). Bioactive esquiterpene lactones from Centaurea species and their cytotoxic/ cytostatic activity against human cell lines in vitro. Planta Medica, 68, 649-52. doi: 10.1055/s-2002-32893

Karamenderes, C., Khan, S., Tekwani, B. L., Jacob, M. R. ve Khan, I. A. (2006). Antiprotozoal and antimicrobial activities of Centaurea species growing in Turkey. Pharmaceutical Biology, 44, 534-539. doi:10.1080/13880200600883080

Köse, Y. B., Demirci, B., Başer, K. H. C. ve Yücel, E. (2008). Composition of the essential oil of three endemic Centaurea species from Turkey. Journal of Esssential Oil Research, 20, 335-338. doi:10.1080/10412905.2008.9700025

Kendir, G. ve Güvenç, A. (2010). Etnobotanik ve Türkiye'de yapılmış etnobotanik çalışmalara genel bir bakış. Hacettepe Üniversitesi Eczacllık Fakültesi Dergisi, 30, 49-80.

Khammar, A. ve Djeddi. S. (2012). Pharmacological and biological properties of some Centaurea species. European Journal of Scientific Research, 84, 398-416. 
Kılıç, Ö. (2015). Türkiye'den iki Centaurea L. (Asteraceae) türünün uçucu yağ kompozisyonu. Düzce Üniversitesi Bilim ve Teknoloji Dergisi, 3, 28-33.

Karaca, B., Akata, I. ve Çöleri Cihan, A. (2017). Antibiofilm and antimicrobial activities of Lentinus edodes, Lactarius delicious and Ganoderma lucidum. Kastamonu University Journal of Forestry Faculty, 17, 660-668. doi:10.17475/kastorman.341971

Mahlo, S. M., Chauke, H. R., McGaw, L., Eloff, J. (2016). Antioxidant and antifungal activity of selected medicinal plant extracts against phytopathogenic fungi. African Journal of Traditional Complementary Alternative Medicine, 13, 216-222. doi: 10.21010/ajtcam.v13i4.28

NCCLS (2000). Methods for dilution and antimicrobial susceptibility tests for bacteria that grow aerobically;approved standard- Fifth Edition. NCCLS document M7-A5, NCCLS: Wayne, PA, USA.

Ozsoy, N., Kultur, S., Yilmaz-Ozden, T., Ozbek Celik, B., Can, A. ve Melikoglu, G. (2015). Antioxidant, anti-Inflammatory, acetylcholinesterase inhibitory and antimicrobial activities of Turkish endemic Centaurea antiochia var. Praealta. Journal of Food Biochemistry, 39, 771-776. doi: $10.1111 /$ jfbc. 12143

Ozkan, G., Kamiloglu, S., Ozdal, T., Boyacioglu, D. ve Capanoglu, E. (2016). Potential use of Turkish medicinal plants in the treatment of various diseases. Molecules, 21, 257. doi: 10.3390/molecules21030257.

Özçelik, S. (1992). Gida mikrobiyolojisi laboratuar k1lavuzu. Firat Üniv Fen-Edebiyat Fak Yayın No:1, 1992; Elazı ̆̆, 85s.

Tekeli, Y., Zengin, G., Aktümsek, A., Sezgin, M. ve Torlak, E. (2011). Antibacterial Activities of Extracts from Twelve Centaurea species from Turkey. Archive Biological Science Belgrade, 63, 685-690. doi:10.2298/ABS1103685T

Taştan, P., Armagan, G., Dağcı, T. ve Kıvçak, B. (2017). Potential cytotoxic activity of Psephellus pyrrhoblepharus extracts. Proceeding, 1, 1047. doi:10.3390/proceedings 1101047

Tozyılmaz, V. (2019). Anadolu florasina ait bazı Endemik türlerin antimikrobiyal, antioksidan ve antibiyofilm aktivitelerinin incelenmesi. Yüksek Lisan Tezi, Bartın Üniversitesi Fen Bilimleri Enstitüsü, Biyoloji AnaBilim Dalı, Bartın. s167.

Tugay, O., Paşayeva, L., Demirpolat, E. ve Şahin, M. (2021). Comparative evaluation of cytotoxicity and phytochemical composition of Centaurea iconiensis (Rhaponticoides iconiensis). Iranian Journal of Science and Technology, Transactions
A: 45, 65-75. https://doi.org/10.1007/s40995-020$01030-y$ 